\title{
USE OF SIMULATION MODELS IN THE PROTECTION OF GROUNDWATER AQUIFER SYSTEMS. APPLICATION AT THE UPPER ANTHEMOUNTAS BASIN IN CHALKIDIKI, GREECE
}

\author{
P. MITSIOS \\ G. TSILONIS \\ N. THEODOSSIOU
}

\author{
Division of Hydraulics and Environmental Engineering, \\ Department of Civil Engineering, \\ Aristotle University of Thessaloniki, \\ 54124 Thessaloniki, Greece
}

Received: 26/08/08

Accepted: 02/02/09 *to whom all correspondence should be addressed: e-mail: niktheod@civil.auth.gr

\begin{abstract}
The importance of the development and application of groundwater simulation mathematical models in the protection of aquifer systems is nowadays recognised as an undisputable fact. In this paper a mathematical model that was developed in order to simulate the operation of the Upper Anthemountas aquifer in Chalkidiki, Greece, is presented. The case study application investigated concerned the possible malfunction of the Waste Water Treatment Plant located within the study area. According to this scenario a possible malfunction of the treatment plant could pollute the underlying aquifer. A network of observation wells located downstream of the plant could detect the pollution and predict the time needed to reach the productive wells surrounding the area. This allows the local water resources managers to formulate a priori action-plans including, the alteration of the pumping schedule in order to prevent polluted water to be abstracted from the nearby wells and at the same time protect the public health, along with necessary measures concerning the prevention of further pollution and the restoration of the groundwater aquifer system.
\end{abstract}

KEYWORDS: Groundwater management, mathematical modelling, groundwater protection, case study.

\section{INTRODUCTION}

Protection and prevention of further pollution of groundwater aquifer systems is one of the main targets of the European Union Water Framework Directive 2000/60. This can only be accomplished in well investigated and accurately simulated aquifers. In order to impose the principles of the directive one needs to develop and apply mathematical simulation models calibrated over the specific characteristics of the aquifer under investigation. The degree of approach between the simulation model and the aquifer system based on both the available data and the assumptions made during the simulation, determines the accuracy of the model and thus the ability to investigate the application of management policies.

One of the most interesting features of the EU directive is the development, organisation and distribution of observation networks. These networks aim both at the enrichment of the available data and at the constant observation of the status of the aquifer system and mainly the quality of groundwater. In order though to accomplish these targets in the less expensive way, the observation networks must be well organised in both their spatial distribution and the schedule of measurements (Theodossiou and Latinopoulos, 2006).

In this paper a mathematical model that was developed through the application of the well known Visual ModFlow software (Waterloo Hydrogeologic Inc., 1999) in order to simulate the function of the Upper Anthemountas aquifer in Chalkidiki in northern Greece, is presented. For the development of the three dimensional simulation model all the available data were 
used including borehole geological sections descriptions, pumping tests results, water uses and rainfall data.

One of the numerous applications of simulation models is the protection of groundwater quality and the prevention of its further pollution. The case study application investigated, concerned the Waste Water Treatment Plant located within the study area. According to this scenario a possible malfunction of the treatment plant could pollute the underlying aquifer. A network of observation wells located downstream of the plant could detect the pollution and predict the time needed to reach the productive wells surrounding the area. This will allow the local water resources managers to take measures including, alteration of the pumping schedule in order to prevent polluted water to be abstracted from the nearby wells and at the same time protect the public health, along with necessary measures concerning the prevention of further pollution and the restoration of the groundwater aquifer system.

\section{USES AND APPLICATIONS OF GROUNDWATER SIMULATION MODELS}

Once a mathematical groundwater simulation model has been created and properly calibrated it can be used in several applications concerning the quantity and quality management of time depended problems. As far as quantity management is concerned such applications could include the prediction of the development of the aquifer according to possible management scenarios (in the future) and the investigation of previously applied water resources related activities (in the past). Respectively quality management applications could include the investigation of the transport of pollutants both forward and backward in time. The investigation of forward in time transport of pollutants is used to determine the vulnerability of the aquifer due to possible pollution incidents as well as the response of the aquifer to rehabilitation actions. On the other hand the investigation of backward in time transport of pollutants can result in the determination of the pollutant source and the application of the "polluter-pays" principle (Theodossiou et al., 2006) as imposed by the water framework directive 60/2000/EC and the 2004/35/EC directive for the environmental liability (Prieur, 2004).

\section{DESCRIPTION OF THE STUDY AREA}

The aquifer of the Upper Anthemountas basin in the Chalkidiki peninsula, in northern Greece, was used as a case study application. The Upper Anthemountas basin, with an area of 90 $\mathrm{km}^{2}$, represents the eastern part of the Anthemountas river basin (Figure 1). The river stretches in a length of $30 \mathrm{~km}$ from west to the east and its basin's total area is about 430 $\mathrm{km}^{2}$. The surface flow of the river is very limited due to both low precipitation and the fact that the upper geological layers consist mainly of permeable and semi-permeable soils. As a result, the river appears to have surface outflows only for a short time after intense rainfall.

The data used in this paper are derived from a research project developed by the Division of Hydraulics and Environmental Engineering of the Aristotle University of Thessaloniki aiming at a more rational water resources management scheme for implementation in the area (Latinopoulos, 2001).

Based on the available data, that included borehole descriptions, geological sections, water level measurements, water uses, pumping tests, rainfall data, field measurements and other relevant data, a mathematical model was formulated (Mitsios and Tsilonis, 2007) using the Visual ModFlow (Waterloo Hydrogeologic Inc., 1999) as simulation software. This three dimensional simulation model is applied over the study area in order to demonstrate one of its possible uses, that of protecting the groundwater quality (Papadopoulou et al., 2005).

\section{THE GROUNDWATER POLLUTION SCENARIO}

The developed groundwater simulation model for the upper Anthemountas aquifer (Latinopoulos, 2001; Mitsios and Tsilonis, 2007) was used in order to investigate the effectiveness of an observation network deployed downstream of the waste water treatment plant located in the area, to identify pollution incidents caused possibly by a malfunction of the plant and provide immediate information concerning the measures that should be taken in 
order first to control the pollution plume that will be generated and second to rehabilitate the aquifer.
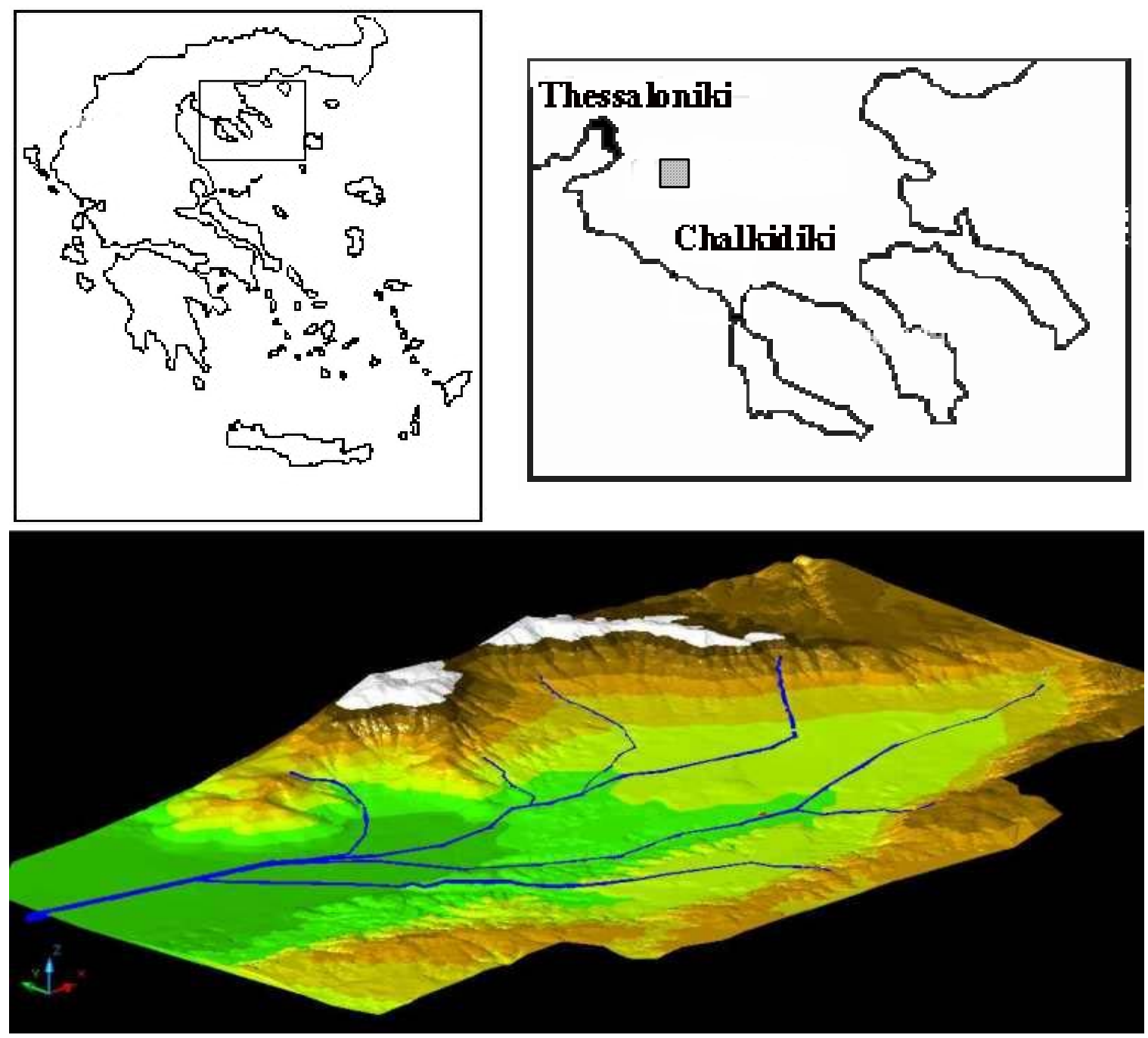

Figure 1. The study area of the upper Anthemountas in Chalkidiki, in northern Greece

The observation network consists of two existing pumping wells located downstream of the treatment plant and upstream of a production water supply well, as shown in figure 2 . It was decided to use two of the numerous existing pumping wells in order to minimize the total cost of the proposed procedure. The first observation well aims at the detection of the pollution as early as possible, while the second assists in the determination of the actual direction of movement and the dimensions of the generated plume, elements that can help the decision makers to take the necessary measures for the protection of the water supply well specifically, and the groundwater quality in general.

An existing well, located about $200 \mathrm{~m}$ downstream the WWTP and on the main direction of flow, was chosen as observation well 1 . The distance from the plant was chosen in order to make certain that the likely pollution will be detected regardless of the actual position of the specific component of the treatment plant that caused the pollution incident.

According to a hypothetical scenario a malfunction at the WWTP resulted in a leak of a pollutant concentration of $500 \mathrm{mg} \mathrm{l}^{-1}$ to the aquifer. The pollutant is considered to be conservative in order to focus on the formation of the plume and its detection by the observation network rather than deal with chemical reactions of specific pollutants. 


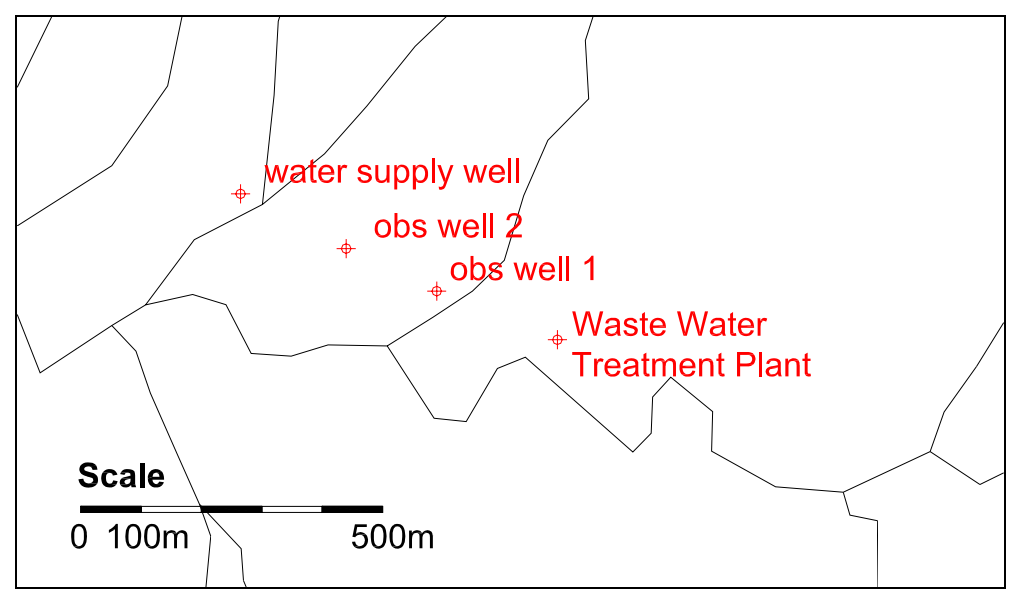

Figure 2. The waste water treatment plant, the observation wells and the water supply well.

Through the application of the simulation model, a number of different scenarios were investigated, according to the frequency of observations. The worst case scenario is produced when the pollution incident arrives at the observation well just after the last sampling. In this case the total time between the start of the leakage, at the plant, and the detection of the pollution incident equals to the sum of travel time and the time interval between two consecutive samples. According to the simulation model, the travel time between WWTP and the first observation well is two months.

As previously mentioned a second observation well is introduced in order to determine the actual direction of movement and the dimensions of the generated plume. This enables the water resources managers to obtain additional information that will assist them to take proper measures for the protection of the aquifer. This information includes a more accurate estimate of the permeability coefficient and of the velocity field formed within the period under investigation. The position of the second observation well was selected among the existing wells located in the middle of the distance between the first observation well and the water supply well. Figure 3 shows the concentration variation with time, at the first observation well (left curve), the second observation well (center surve) and the under protection water supply well (right curve), under the do nothing scenario. It is obvious that the pollution detected at the observation well will result in pollution of the groundwater abstracted by the water supply well.

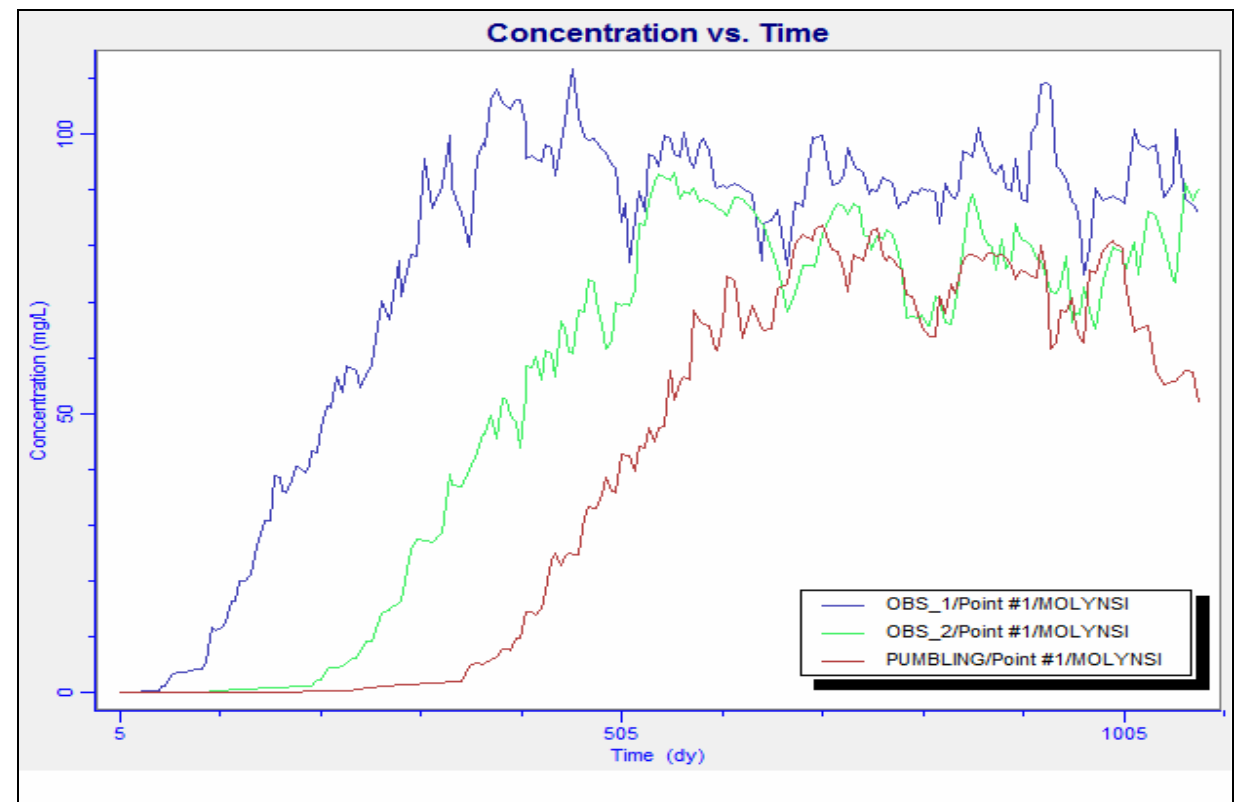

Figure 3. Concentration versus time at the first observation well on the left, the second observation well in the middle and the water supply well on the right 
A number of different scenarios were investigated according to the time interval between succesive samplings, at the observation well, thus determining the time of detection of the pollution incident. According to these scenarios when a pollutant concentration above normal is measured, at the first observation well, the waste water treatment plant must immediately stop functioning in order to prevent further pollution of the aquifer.

Seven different time intervals were investigated. According to the first one (indicated as 0 months) in table 1 and figure 4, the sampling coinsides with the arrival of the pollution plume at the observation well. All the other scenarios refer to the time interval between successive samplings and thus between sampling and the time of arrival of pollutant plumes. It is obvious that the sooner the detection of the pollution incident the better for the protection of the groundwater quality. In the third column of table 1, the maximum concentration of the pollution plume arriving at the water supply well is indicated, while in the fourth column the duration of a concentration of pollutant above the limit of $5 \mathrm{mg} \mathrm{l}^{-1}$ is presented. In the last column, an index of the persistance of the pollution is introduced.

The persistance of pollution is defined as the product of the maximum plume concentration, arriving at the water supply well, and the number of days the quality of water removed from the protected well is affected by the pollution incident.

Table 1. Analysis of the impact of frequency of measurements at the observation well 1 at the quality of water abstracted at the water supply well

\begin{tabular}{ccccc}
\hline $\begin{array}{c}\text { Interval between } \\
\text { Samplings } \\
\text { (months) }\end{array}$ & $\begin{array}{c}\text { Days from start } \\
\text { of pollution }\end{array}$ & $\begin{array}{c}\text { Maximum } \\
\text { Concentration } \\
\left(\mathrm{mg} \mathrm{l}^{-1}\right)\end{array}$ & $\begin{array}{c}\text { Duration of } \\
\text { Pollution } \\
\text { (days) }\end{array}$ & $\begin{array}{c}\text { Persistence } \\
\text { Index } \\
\left.\text { (days mg I } \text { I }^{-1}\right)\end{array}$ \\
\hline 0 & 60 & 11 & 230 & 2530 \\
\hline 1 & 90 & 14 & 270 & 3780 \\
\hline 2 & 120 & 21 & 300 & 6300 \\
\hline 3 & 150 & 30 & 380 & 11400 \\
\hline 4 & 180 & 60 & 420 & 25200 \\
\hline 5 & 210 & 70 & 500 & 35000 \\
\hline 6 & 240 & 75 & 550 & 41250 \\
\hline
\end{tabular}

It is obvious that the less the persistence index the better the solution. One can easily observe, from figure 4 , that a critical point in the selection of the time interval between samplings is reached at the three months interval. A sampling interval that exceeds three months, increases significantly the persistence of pollution index and can result in a very dangerous situation for the quality of water removed from the water supply well.

Another interesting conclusion is derived by the difference between the concentrations measured simultaneously at the two observation wells. After a number of successive application of the simulation model for different values of the leakage from the waste water treatment plant, the values of the concentrations recorded simultaneously at the two observation wells were calculated, as well as the resulting maximum concentration arriving at the water supply well. Figure 5 was produced through the combination of all of these parameters. It indicates the relation between the leakage from the pollution source, the maximum concentration expected to arrive at the water supply well, and the difference between the observed concentrations at the two observation wells. The development of figure 5 allows the water resources managers, when measuring the concentrations at the two observation wells, to estimate the characteristics of the pollution incident (leakage rate) and mainly to predict the magnitude of the problem, at the water supply well (maximum concentration), and take the necessary measures. 

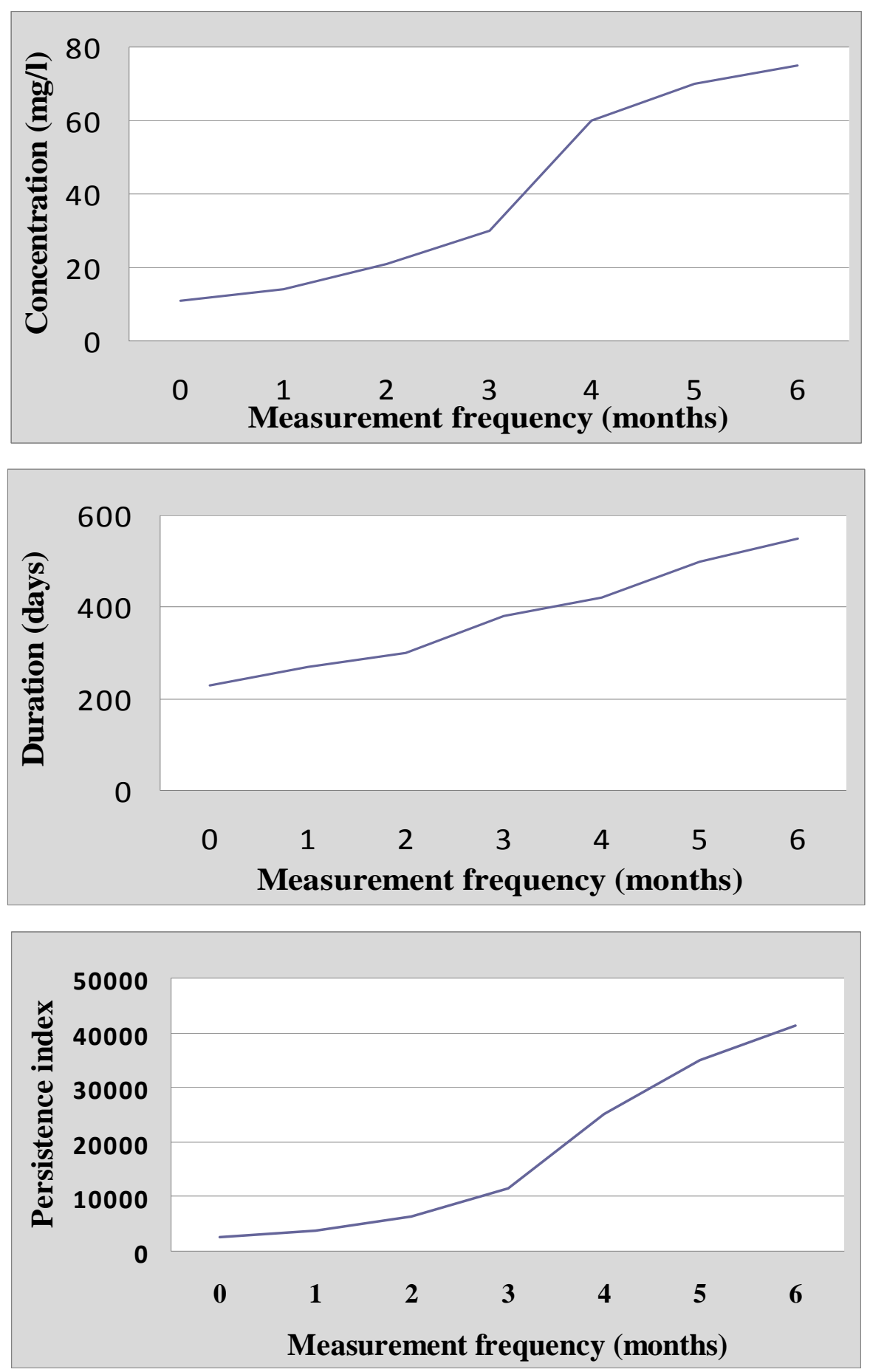

Figure 4. Analysis of the impact of the frequency of measurements at the observation well-1 on the quality of water removed from the water supply well

(a) Maximum concentration observed according to the measurement frequency

(b) Maximum duration of concentration over the limit of $5 \mathrm{mg} \mathrm{l}^{-1}$

(c) The persistence index of the measurement schedule 


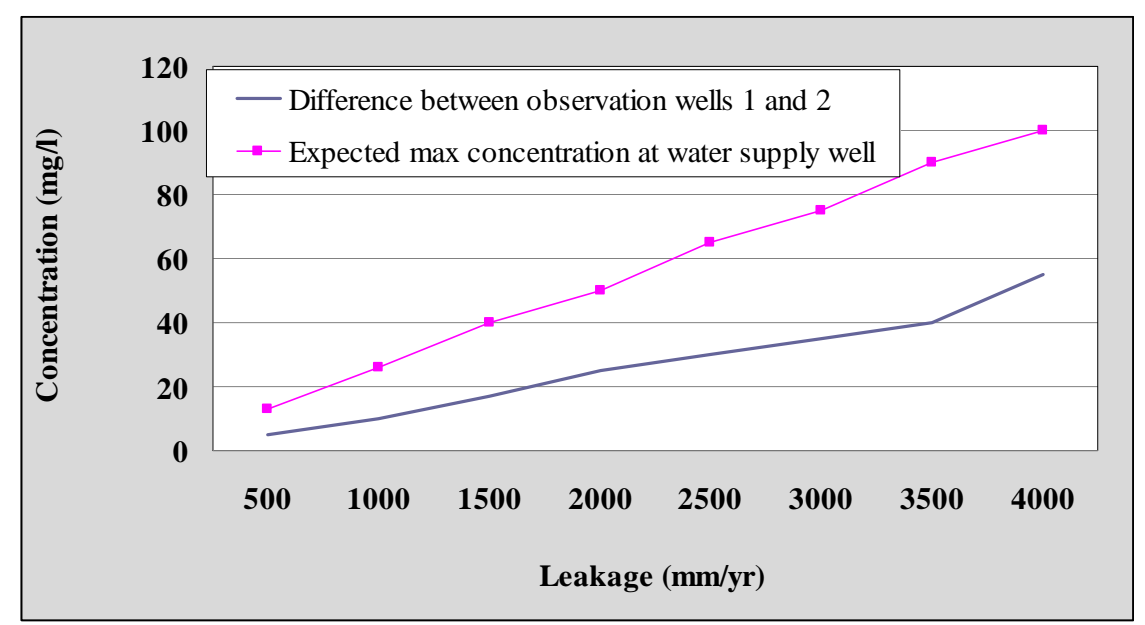

Figure 5. Estimation of the leakage rate of the pollution source and the expected maximum concentration at the water supply well based on the concentrations at the observation wells

\section{CONCLUSIONS}

In this paper, an application of a mathematical groundwater simulation model for improving the operation of an observation network aiming at the protection of groundwater quality of the Upper Anthemountas basin, was presented. The application of the tools used point out the need for further development of simulation models in order to protect groundwater aquifer systems.

Based on a hypothetical scenario that a malfunction of the waste water treatment plant will generate pollution in the underlying aquifer, the effectiveness of the observation network is investigated. The effectiveness of this network is based on the position of the observation wells, relative to the waste water treatment plant, to each other and relative to the water supply well.

The findings of this work are useful to the water resources managers. The fact that one can explore the impact of these scenarios a priori, at the stage of development of the waste water treatment plant, or during of whatever possible pollution activity, enables the operators managers to formulate action-plans that can be immediately applied at the time of observation of a pollution incident and thus prevent the development of a more serious situation that will be hard to deal with later.

\section{REFERENCES}

Latinopoulos P., (2001). Investigation and exploitation of the water resources in the basin of Upper Anthemountas, Research Project, Faculty of Civil Engineering, A.U.T., Thessaloniki.

Mitsios P. and Tsilonis G., (2007). Groundwater simulation models. The upper Anthemountas aquifer in Chalkidiki, Graduate thesis, Department of Civil Engineering, Aristotle University of Thessaloniki.

Papadopoulou M.A, Karatzas G.P., Koukadaki M.A and Trichakis Y., (2005). Modeling the saltwater intrusion phenomenon in coastal aquifers - A case study in the industrial zone of Herakleio in Crete, Global Nest Journal, 7(2), 197-203.

Prieur M., (2004), La responsabilité environmentale en droit communautaire, Revue Européenne de droit de l'environnement, (2).

Theodossiou N. and Latinopoulos P., (2006), Evaluation and optimization of groundwater observation networks using the Kriging methodology, Environmental Modelling and Software, 21, 991-1000. (Corrigendum published in 22, 414, 2007).

Theodossiou N., Latinopoulos P., Karatzas G.P. and Maria E.A., (2006), Delineation of capture zones in groundwater aquifers as a tool for the application of the "polluter-pays" principle, International Conference on Protection and Restoration of the Environment VIII, Chania.

Waterloo Hydrogeologic Inc., (1999), Visual MODFLOW version 2.8.1. 